\title{
New records of five coral diseases from the Pilbara Region of Western Australia
}

Received: 23 May 2010/ Accepted: 27 June 2010/Published online: 16 July 2010

(C) Springer-Verlag 2010
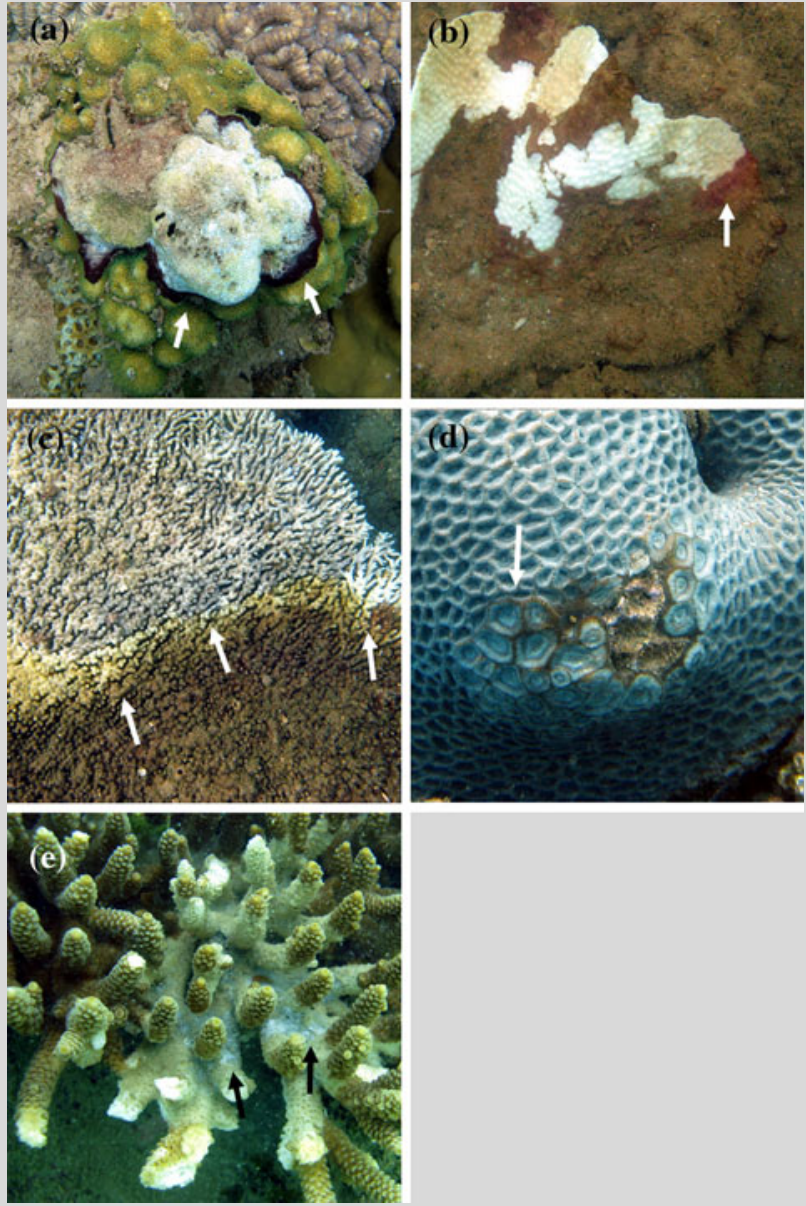

Fig. 1 Examples of a black band disease, b non-black cyanobacterial infections, $\mathbf{c}$ white syndrome, $\mathbf{d}$ growth anomalies, and $\mathbf{e}$ a disease resembling atramentous necrosis, affecting Pilbara corals
Examination of photographs and histological preparations of corals from the nearshore waters of Mermaid Sound and Cape Lambert in the remote Pilbara Region of Western Australia (WA) revealed the persistent presence of five coral diseases over $\sim 3$-years (January 2007 to November 2009). The five diseases identified were black band disease (Fig. 1a), non-black cyanobacterial infections (Fig. 1b), white syndrome (Fig. 1c), growth anomalies (Fig. 1d), and a disease resembling atramentous necrosis (Fig. 1e). These diseases are known from other Indo-Pacific regions, and some even from the Caribbean (Harvell et al. 2007). However, none have been noted previously in the numerous studies of corals in the Pilbara Region conducted over several decades. In fact, no published records of coral disease exist for the entire WA coast. In the absence of previous disease records from the Pilbara Region, these recent records of disease raise two important questions. Have the distributions of these diseases expanded recently in the Indian Ocean? Or, do these disease records simply reflect an increased interest in diseases from trained observers in this remote region? In either event, these records of five coral diseases from the Pilbara highlight the urgent need for baseline studies of diseases affecting corals in this and other regions of WA.

Acknowledgments This research was funded by the Dampier Port Authority, Pilbara Iron Pty Limited and Woodside. Thanks also to the MScience field team for colony photography and sample collection.

\section{Reference}

Harvell CD, Jordan-Dahlgren E, Merkel SM, Rosenberg E, Raymundo LJ, Smith G, Weil E, Willis BL (2007) Coral disease, environmental drivers and the balance between coral and microbial associates. Oceanography 20:36-59

C. A. Page $(\bowtie) \cdot$ J. A. Stoddart

MScience Pty Ltd, 239 Beaufort St, Perth, WA 6003, Australia e-mail: CathiePage@iinet.net.au

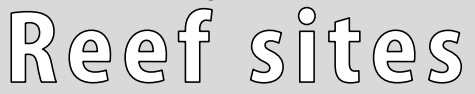

Coral Reefs (2010) 29:987

DOI $10.1007 / \mathrm{s} 00338-010-0659-5$ 